\title{
Exome analysis of carotid body tumor
}

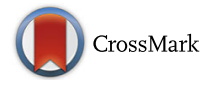

\author{
Anastasiya V. Snezhkina ${ }^{1 \dagger}$, Elena N. Lukyanova ${ }^{1 \dagger}$, Dmitry V. Kalinin², Anatoly V. Pokrovsky², Alexey A. Dmitriev', \\ Nadezhda V. Koroban³ ${ }^{3}$ Elena A. Pudova', Maria S. Fedorova', Nadezhda N. Volchenko³, Oleg A. Stepanov ${ }^{1,3}$, \\ Ekaterina A. Zhevelyuk', Sergey L. Kharitonov', Anastasiya V. Lipatova', Ivan S. Abramov', Alexander V. Golovyuk², \\ Yegor E. Yegorov', Khava S. Vishnyakova', Alexey A. Moskalev', George S. Krasnov', Nataliya V. Melnikova', \\ Dmitry S. Shcherbo ${ }^{4}$, Marina V. Kiseleva ${ }^{3}$, Andrey D. Kaprin ${ }^{3}$, Boris Y. Alekseev ${ }^{3}$, Andrew R. Zaretsky ${ }^{4}$ \\ and Anna V. Kudryavtseva ${ }^{1,3^{*}}$
}

From Belyaev Conference

Novosibirsk, Russia. 07-10 August 2017

\begin{abstract}
Background: Carotid body tumor (CBT) is a form of head and neck paragangliomas (HNPGLs) arising at the bifurcation of carotid arteries. Paragangliomas are commonly associated with germline and somatic mutations involving at least one of more than thirty causative genes. However, the specific functionality of a number of these genes involved in the formation of paragangliomas has not yet been fully investigated.

Methods: Exome library preparation was carried out using Nextera ${ }^{\circledR}$ Rapid Capture Exome Kit (Illumina, USA). Sequencing was performed on NextSeq 500 System (Illumina).

Results: Exome analysis of 52 CBTs revealed potential driver mutations (PDMs) in 21 genes: ARNT, BAP1, BRAF, BRCA1, BRCA2, CDKN2A, CSDE1, FGFR3, IDH1, KIF1B, KMT2D, MEN1, RET, SDHA, SDHB, SDHC, SDHD, SETD2, TP53BP1, TP53BP2, and TP53/13. In many samples, more than one PDM was identified. There are also 41\% of samples in which we did not identify any PDM; in these cases, the formation of CBT was probably caused by the cumulative effect of several not highly pathogenic mutations. Estimation of average mutation load demonstrated 6-8 mutations per megabase (Mb). Genes with the highest mutation rate were identified.
\end{abstract}

Conclusions: Exome analysis of 52 CBTs for the first time revealed the average mutation load for these tumors and also identified potential driver mutations as well as their frequencies and co-occurrence with the other PDMs.

Keywords: Carotid body tumor, Paragangliomas, Head and neck paragangliomas, Mutations, High-throughput sequencing, Exome

\section{Background}

Carotid body tumors (CBTs) are neoplasms of the paraganglia located at the bifurcation of carotid arteries and belong to head and neck paragangliomas (HNPGLs). These highly vascularized tumors originate in the neural crest and are typically benign. However, in $10-15 \%$ of cases the tumors can become malignant, characterized

\footnotetext{
* Correspondence: rhizamoeba@mail.ru

${ }^{\dagger}$ Equal contributors

'Engelhardt Institute of Molecular Biology, Russian Academy of Sciences, Moscow, Russia

${ }^{3}$ National Medical Research Radiological Center, Ministry of Health of the Russian Federation, Moscow, Russia

Full list of author information is available at the end of the article
}

by multifocal growth, metastases, and relapse after surgical treatment. Typically, CBTs are slow-growing tumors. Surgical treatment remains high-risk and extremely challenging due to the location of the tumor in close proximity of important nerves and blood vessels. Potential damage to carotid arteries can result in cerebral circulation dysfunction [1]. One of the main difficulties in CBT management is the identification of tumors that are predisposed to be aggressive, since morphological criteria alone are not sufficiently informative [2]. To create more specific treatment strategies, there is a growing need for identification of new biomarkers that can distinguish between indolent and aggressive metastatic forms of CBTs. 
Many germline and somatic mutations are involved in progression of paragangliomas (PGLs). Up to $30-40 \%$ of all HNPGLs are hereditary [3, 4]. The majority of these familial paraganglioma syndromes are due to mutations in genes encoding distinctive subunits of the mitochondrial succinate dehydrogenase (SDH) complex [5]. The SDH complex participates in both the citric acid cycle and the electron transport chain, playing an essential role in energy metabolism. Besides, somatic mutations in more than 30 causative genes are described as drivers for paragangliomas [6-9].

The Cancer Genome Atlas (TCGA) consortium published the results of comprehensive molecular profiling including exome, mRNA, and miRNA sequencing, epigenomic analysis as well as reverse phase protein array for 173 pheochromocytoma (PCC) and paraganglioma tumors [10]. Four molecular subtypes were revealed in this work. Unfortunately, HNPGLs were not included in the analysis because such tumors are often embolized prior to surgery, leaving excessive necrotic tumor tissue that is insufficient for molecular analysis. The majority of researches include PGLs from many localizations and PCC in a single group, therefore it is impossible to determine the frequency of mutations in particular genes in tumors with different localizations $[2,11]$. This work is dedicated to exome analysis of carotid paragangliomas for understanding the difference in causative gene set and frequency of mutations with other PGLs.

Somatic mutations occur in all cancer types [12]. In some of them, a part of somatic mutations is generated by exposures such as tobacco smoking in lung cancer and ultraviolet light in cutaneous melanoma [13], or by abnormalities of DNA maintenance as a defective DNA mismatch repair in some colorectal tumors [14]. Different mutational processes often generate different combinations of mutation types termed "signatures" [15]. Using high-throughput sequencing technology, thousands of somatic mutations can be identified in each tumor sample, and it was demonstrated that it is not correct to include only "driver" mutations in the analysis of signatures of mutational processes and mutation load (ML) [12]. Therefore, the sequencing of blood or adjusted normal tissue is used for revealing germline mutations, except ML analysis. Variant filtering by frequency in healthy population can be used to exclude potentially germline mutations in absence of non-tumor tissue. Then ML is estimated as a number of mutations per megabase $(\mathrm{Mb})$ of coding regions. It was recently observed that the samples with high mutation load among the other samples in the same cancer type are more sensitive to immunotherapy, which can be very promising for tumor treatment [16-19]. This is the first reported data on mutation load and its range in CBTs.

\section{Methods}

Tissue sample collection and nucleic acid isolation

The paraffin-embedded tissues of 52 CBTs were collected at the Vishnevsky Institute of Surgery, Ministry of Health of the Russian Federation. The sections from paraffinembedded tissues were prepared on glass slides and then stained with hematoxylin-eosin (H\&E). Tumor areas were chosen in unstained sections according to the reference H\&E slide and transferred into microcentrifuge tubes. DNA was isolated using the High Pure FFPET DNA Isolation Kit (Roche, Switzerland). DNA concentrations were measured using NanoDrop 1000 spectrophotometer (Thermo Fisher Scientific, USA) in addition to Qubit 2.0 fluorimeter (Thermo Fisher Scientific). DNA quality was estimated using the Agilent 2100 Bioanalyzer (Agilent Technologies, USA). The cohort consisted of Russian citizens with both familial and sporadic forms, 3280 years, predominantly women (61\%) requested for surgical treatment of CBTs. Patient's consent for the study was obtained, and the protocol for investigation was approved by the ethical committee according to the preliminary discussion and agreement.

\section{Library preparation, sequencing, and analysis}

Library preparation for exome sequencing was carried out using the Nextera ${ }^{\circ}$ Rapid Capture Exome Kit (Illumina, USA). Sequencing was performed using NextSeq 500 System (Illumina). At least 60 million paired-end reads of 75 nucleotides in length were obtained for each sample with $300 \times$ minimal coverage.

Raw data from high-throughput sequencing in ".fatsq.gz format were aligned on hg19 reference human genome using bwa mem software. The resulting files of ".bam format were sorted and deduplicated using the SAMtools program package. Mutation calling was performed with freebayes software with filtration of identified variants with vcffilter of vcflib program package. Annotation of variants was performed using SnpSift of snpEff program package. Databases dbSNP, dbNSFP, ClinVar, MutationTaster, SIFT, PolyPhen-2, FATHMM, phastCons, PhyloP, 1000 Genomes Project, ExAC, COSMIC, GO, ConsensusPathDB, and OMIM were used as information resources for identified variants.

List of genes, which can have potential driver mutations (PDMs) involved in PGL formation, was created based on detailed literature analysis including exome sequencing results of TCGA project (http://cancergenome.nih.gov/) $[2,10]$. Then PDMs in selected genes were analyzed for 52 CBT samples and characterized. We determined all non-synonymous mutations and then applied a set of filters to discriminate mutations that can be drivers for CBTs (Additional file 1). We did not discriminate somatic and germline mutations at this step because both of them can cause PGLs in a similar way, 
as well as we did not have access to blood or matched non-tumor tissue for many FFPE samples collected since 1990.

Mutation load analysis was performed for all samples. Variants observed in healthy population were excluded as potentially germline mutations. Therefore, we used stringent parameters for filtration, and potentially somatic deleterious mutations were counted to estimate their number per megabase of coding regions [12].

\section{Results}

The list of 42 potentially causative genes for PGLs was created: VHL, SDHA, SDHB, SDHC, SDHD, NF1, RET, HRAS, KRAS, EPAS1 (HIF2A), ATRX, CSDE1, BRAF, FGFR1, FGFR2, FGFR3, FGFR4, FGFRL1, SETD2, ARNT, TP53, TP53BP1, TP53BP2, TP53I13, KMT2D, BAP1, IDH1, IDH2, SDHAF1, SDHAP2, FH, EGLN1, MDH2, TMEM127, MAX, KIF1B, MEN1, GDNF, GNAS, CDKN2A, BRCA1, and $B R C A 2$. Selected genes are involved in many important pathways including TCA cycle, DNA repair, oxidative phosphorylation, HIF-1 signaling pathway, Ras signaling pathway, PI3K-Act signaling pathway, carbon metabolism, etc. (Fig. 1, Additional file 2). Moreover, many of them are causative for different cancer types and other diseases (Fig. 2, Additional file 2). These genes were analyzed in CBTs, and high impact mutations were identified in 32 genes. Potential driver mutations were found only in 21 of them: ARNT, BAP1, BRAF, BRCA1, BRCA2, CDKN2A, CSDE1, FGFR3, IDH1, KIF1B, KMT2D, MEN1, RET, SDHA, SDHB, SDHC, SDHD, SETD2, TP53BP1, TP53BP2, and TP53I13. In $27 \%$ of CBT samples, more than one potential driver mutation was observed. Two PDMs were found in the same gene in two samples. The results are summarized in Fig. 3, Fig. 4, Table 1, and Additional file 3.

\section{SDHx}

Mutations in genes encoding succinate dehydrogenase (SDH) subunits can cause pseudohypoxic state in PGLs and PCC. SDH comprises a mitochondrial protein complex that participates in both the Krebs cycle and the electron transport chain. In the Krebs cycle, this complex oxidizes succinate to fumarate, whereas, in the transport chain, it transfers electrons onto coenzyme Q [20]. The SDH enzyme complex consists of four subunits: $S D H A, S D H B$, $S D H C$, and $S D H D$, which form the core of the complex as well as its structural fastening elements [21]. Two

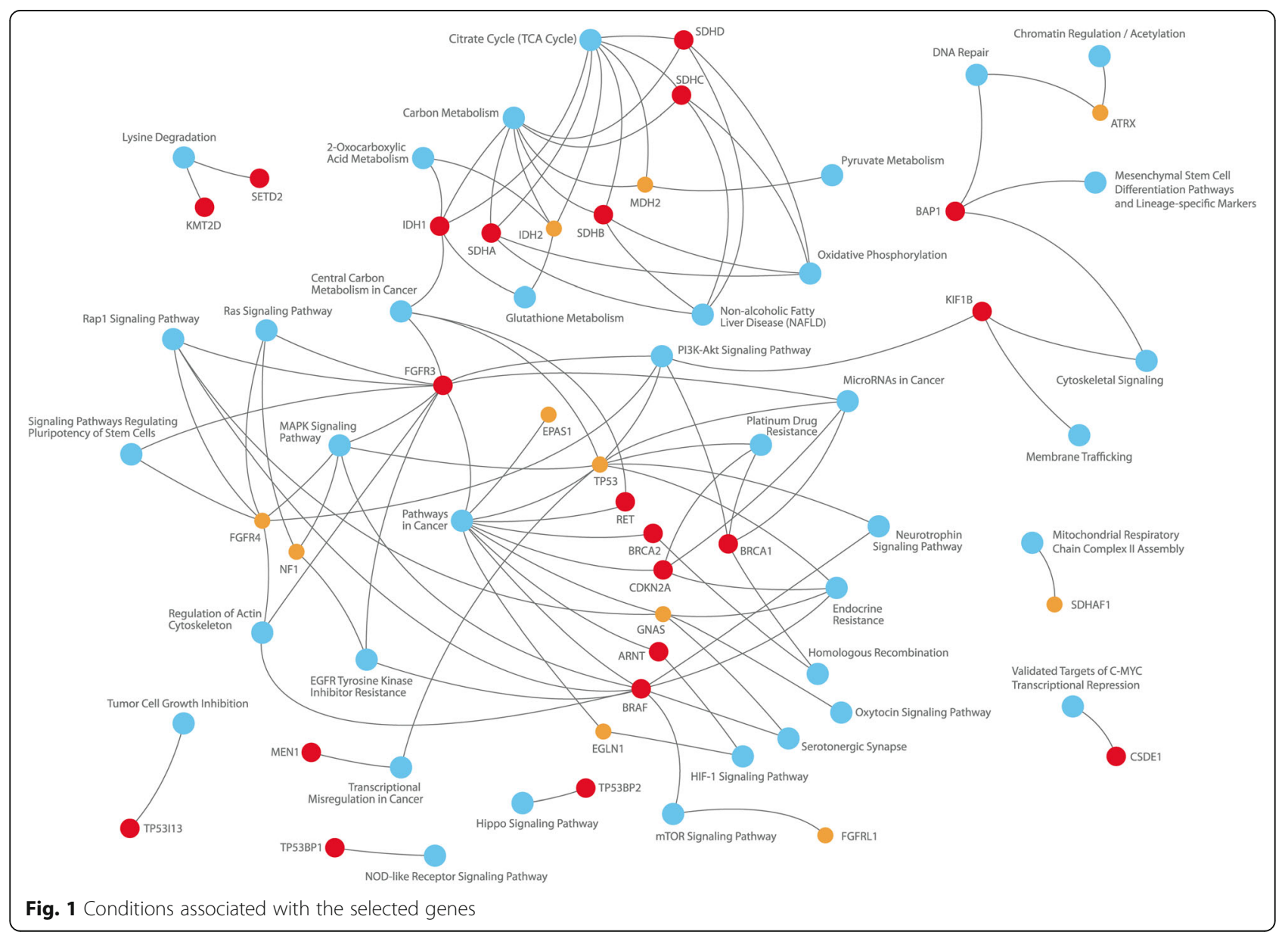




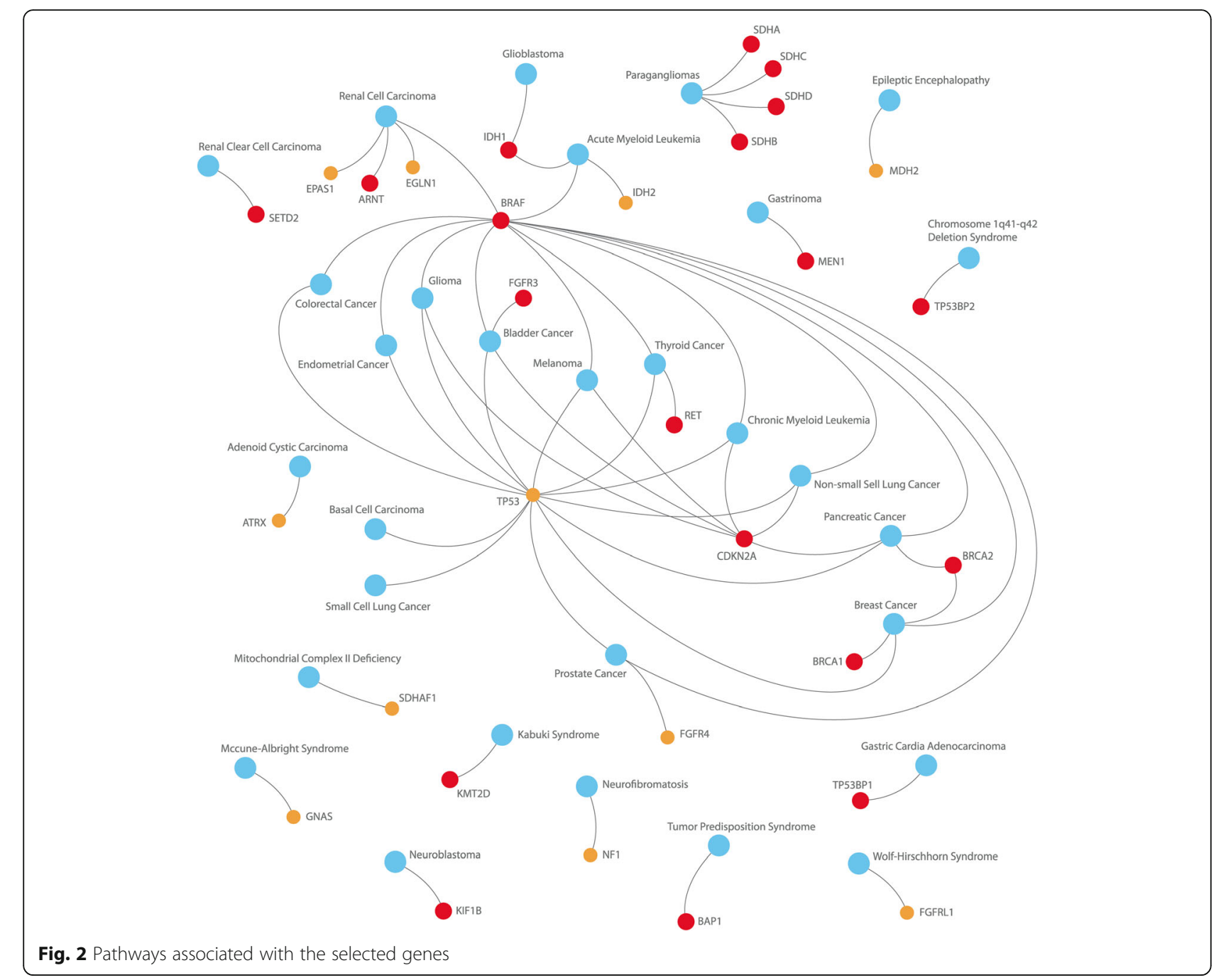

more factors are also involved in the assembly of the complex: SDHAF1 [22] and SDHAF2 [23]. Therefore, a mutation in any of these genes, collectively termed $S D H x$ genes, would impair the structure of the entire complex leading to oncogenesis [24]. Generally, germline mutations in the SDHx genes lead to heritable PGLs, PCC, and other tumors.

\section{SDHA}

Only one potential driver missense mutation NM_004168: c.792C > A, p.(Phe264Leu) (chr5:231,012) was identified in SDHA gene. Information on this mutation in dbSNP, ClinVar, Cosmic, and Ensembl databases is absent, but predictor programs demonstrate high probability for it to be pathogenic one.

\section{$S D H B$}

We identified four mutations in $S D H D$ gene. PDM NM_003000: c.541-2A > G (chr1:17,350,571, rs786201161) is located in splice-site described in ClinVar as germline mutation with pathogenic or probably pathogenic clinical significance. It was found in different phenotypic conditions including hereditary cancer-predisposing syndrome, PGLs and PCC [25, 26], leukoencephalopathy [27], as well as kidney cancer [28].

A mutation NM_003000: c.724C $>$ T, p.(Arg242Cys) (chr1:17,349,144, rs786203251) is deposited as germline pathogenic one and described as a risk factor for PGLs, PCC, and hereditary gastro-intestinal stromal tumor. A mutation NM_003000: c.763A > T, p.(Lys255*) (chr1:17, 349,105) is included only in Ensembl database.

Two mutations, NM_003000: c.233A > G, p.(Lys78Arg) (chr1:17,359,608, rs774960237) and NM_003000: c.763A > T, p.(Lys255*) (chr1:17,349,105), do not have description of clinical effect in databases. In sample "Pat11" (Fig. 4), only the $S D H B$ mutation c.763A > T was identified among selected genes of interest. It is located in the last codon of the second to last exon and forms stop-codon. However, it is indicated as nonpathogenic mutation by the SIFT predictor resource that 


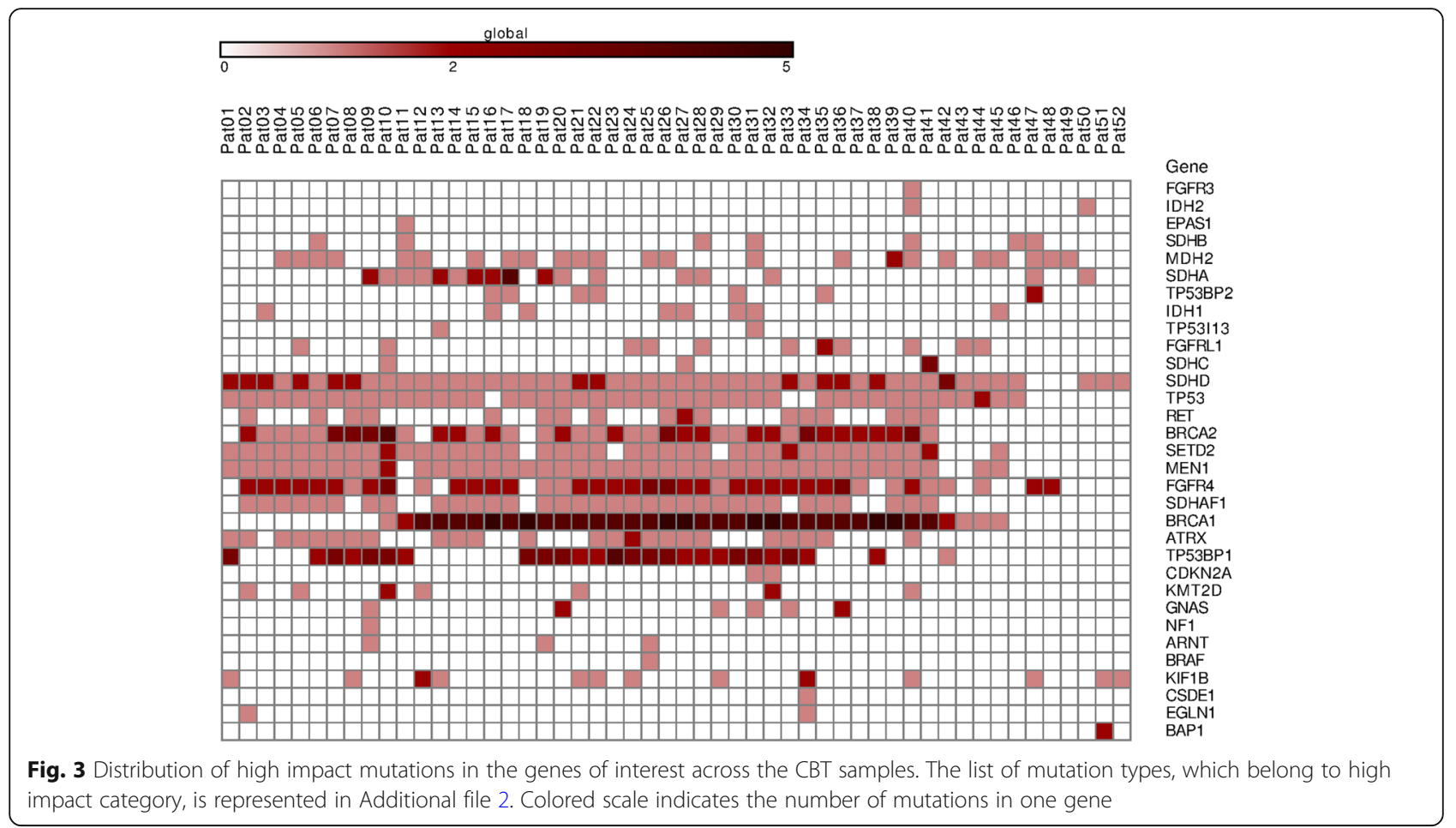

can be explained by the algorithm of prediction ignoring changes in the end of protein.

Mutation c.233A $>\mathrm{G}$ has a very low frequency in population $(0.000008 / 1$, according to ExAC) and is probably germline one. According to SIFT resource, this mutation is not pathogenic. In sample "Pat31", it co-occurs with PDMs in IDH1 and TP53I13 genes and probably acts as the initial driver which needs to be activated with other pathogenic influences such as additional somatic mutations.

\section{$S D H C$}

We identified three samples with $S D H C$ mutations, one of them contained two different PDMs, NM_003001: c.224G > A, p.(Gly75Asp) (chr1: 161,310,428, rs786205147) and NM_003001: c.7G > A, p.(Ala3Thr) (chr1:161,284,202,

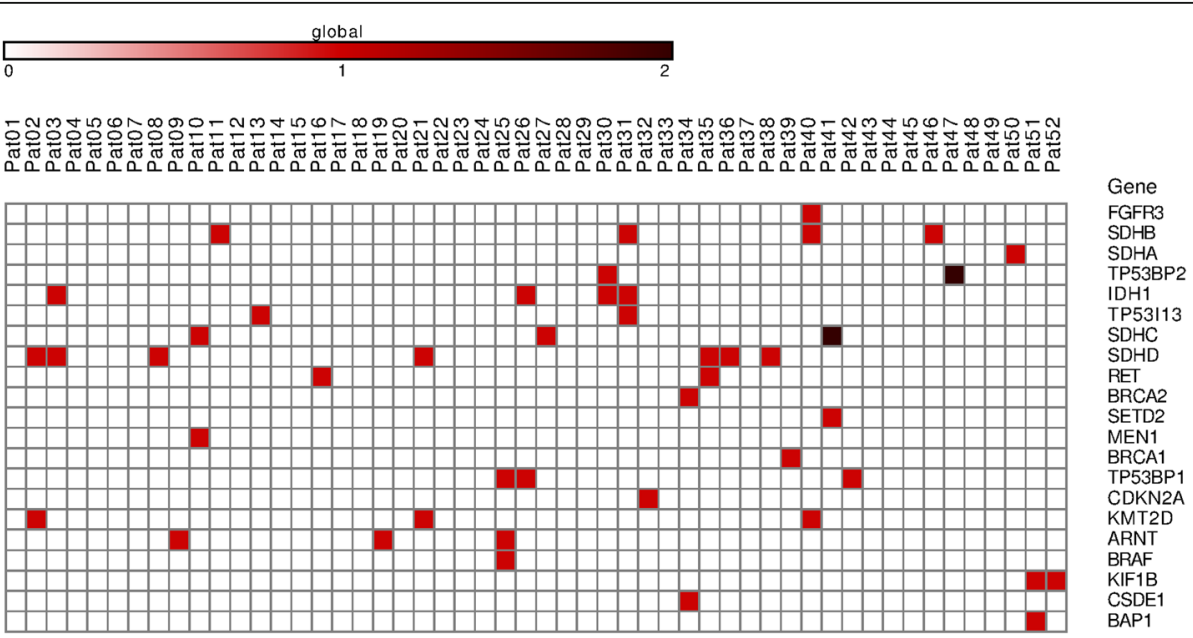

Fig. 4 Distribution of potential driver mutations in the genes of interest across the CBT samples. For PDM determination, we apply three additional filters for the previous list. We included mutations occurring only in healthy human population with less than $2 \%$ frequency according to the ExAC database and 1000 Genomes project. Only mutations reported as benign according to ClinVar were removed. We suggested that PDMs are only those mutations which are located in conservative DNA fragments. Fragments with conservative score higher than 0.6 (scale: from 0 - highly variable fragment, to 1 - highly conservative fragment) according to phastCons for three groups (46 placentals, 46 primates, and 100 vertebrates) were included. Colored scale indicates the number of mutations in one gene 
Table 1 Frequency of potential driver mutations (PDMs) in the selected genes, and their co-occurrence in carotid body tumor (CBT) samples

\begin{tabular}{lll}
\hline Gene & $\begin{array}{l}\text { Frequency of samples } \\
\text { with mutations, \% }\end{array}$ & $\begin{array}{l}\text { Associations with mutations } \\
\text { in the other genes }\end{array}$ \\
\hline SDHD & 13.5 & RET, KMT2D, IDH1 \\
IDH1 & 7.7 & $\begin{array}{l}\text { SDHB, SDHD, TP53BP1, } \\
\text { TP53BP2, TP53/13 }\end{array}$ \\
SDHB & 7.7 & IDH1, FGFR3, TP53/13, KMT2D \\
ARNT & 5.8 & BRAF, TP53BP1 \\
SDHC & 5.8 & SDHC, SETD2,MEN1 \\
KMT2D & 5.8 & SDHD, SDHB, FGFR3 \\
TP53BP1 & 5.8 & ARNT, BRAF, IDH1 \\
TP53BP2 & 3.8 & TP53BP2, IDH1 \\
TP53/13 & 3.8 & IDH1, SDHB \\
RET & 3.8 & SDHD \\
KIF1B & 3.8 & BAP1 \\
CDKN2A & 1.9 & - \\
BRAF & 1.9 & ARNT, TP53BP1 \\
BRCA2 & 1.9 & CSDE1 \\
BAP1 & 1.9 & KIF1B \\
CSDE1 & 1.9 & BRCA2 \\
SETD2 & 1.9 & SDHC \\
MEN1 & 1.9 & SDHC \\
FGFR3 & 1.9 & SDHB, KMT2D \\
BRCA1 & 1.9 & - \\
SDHA & 1.9 & - \\
\hline G & & \\
\hline
\end{tabular}

Genes which have two mutations in one sample are indicated with bold

rs748243732). PDM c.224G $>$ A is described in dbSNP as germline mutation, and it is indicated in ClinVar as probably pathogenic one, because it was found as a rare single nucleotide variant (SNV) in patient with Karney's triad (it seems to be a sporadic disease). PDM c.7G > A was described as a rare germline mutation with unknown clinical significance in gastro-intestinal stromal tumors and PGLs. According to SIFT, its parameter is close to a threshold of 0.08 (pathogenic < 0.05). Besides, the mutation is predicted as pathogenic one by PolyPhen- 2 and LRT (likelihood ratio test) and is located in a highly conservative DNA region by phastCons prediction. However, MutationTaster predicts it as non-pathogenic mutation. Therefore, we can suggest that patient has non-highly pathogenic mutations in both copies of $S D H B$ or in the same copy that caused cumulative effect and became the reason for tumor growth.

A nonsense mutation NM 003001: c.183G > A, p.(Trp61*) $($ chr1:161,310,387) was observed in one sample. It was described only in HGMD resource (CM092024), and its clinical significance was not indicated. However, the stop-codon in the middle of ORF suggested it being pathogenic mutation.

One deletion undescribed in databases NM_003001: c.409delT, p.(Trp137fs) (chr1:161,332,121) was identified in gene $S D H C$. It leads to frameshift, which is a strong prediction factor of pathogenicity. Moreover, the stop-codon located near the frameshift in codon 133 (p.(Arg133Ter)) is represented in databases and associated with PGLs.

\section{$S D H D$}

We identified SDHD mutations in seven CBT samples. In two samples, it was a nonsense mutation NM_003002: c.112C > T, p. $\left(\operatorname{Arg} 38^{*}\right)$ (chr11:111,958,640, rs80338843). It is described in databases as a germline pathogenic mutation associated with hereditary paragangliomas, pheochromocytoma, as well as gastric stromal sarcoma $[4,5]$.

A mutation NM_003002: c.205G > T p.(Glu69*) (chr11:111,959,626) was found in one of the samples. Its description in NCBI and Ensembl databases is absent, but another mutation in the same codon is deposited in Cosmic and ClinVar as germline pathogenic one [29] (NM_003002: c.205G > A, p.(Glu69Lys)). Thus, a mutation c.205G $>\mathrm{T}$ forming stop-codon also appears to be pathogenic one that is confirmed by data from SIFT, MutationTaster, LRT, and phastCons resources.

Mutation NM_003002: c210G > C, p.(Arg70Ser) was found in one sample. Data from NCBI and Ensembl resources are absent. A similar mutation c209G $>$ A, p.(Arg70Lys) in the same codon is described in ClinVar with unknown clinical significance. It is deposited in Cosmic database as germline pathogenic mutation according to FATHMM data, which is also supported by all prediction resources: SIFT, PolyPhen-2, MutationTaster, and LRT. Moreover, it is located in highly conservative DNA region by phastCons information. This fact may suggest the pathogenic effect of mutation $\mathrm{c} 210 \mathrm{G}>\mathrm{C}$.

Three mutations causing frameshift, that usually has a highly pathogenic effect, were evaluated - NM_003002: c.217dupA, p.(Ser73fs) (chr11:111,959,637), NM_003002: c.220_228delGTT TTG CTCinsT, p.(Val74fs) (chr11:111, 959,639), and NM_003002: c.13dupT, p.(Trp5fs) (chr.11: 111,957,643). Germline mutation in the same codon c.14G > A, leading to hereditary PCC, was described earlier [4].

\section{IDH1}

In the TCA cycle, IDH comprises the oxidative decarboxylation enzyme that converts isocitrate to $\alpha$ ketoglutarate. Under conditions of hypoxia or in tumor cells with defective mitochondria, this enzyme participates in the reductive carboxylation of $\alpha$-ketoglutarate to isocitrate during glutamine-dependent lipogenesis [30].

We found mutation NM_005896: c.548A > G, p.(Tyr183Cys) (chr2:209,108,301, rs34599179) in two samples and 
mutation NM_005896: c.94 T > G, p.(Phe32Val) (chr2:209, 116,182 , rs142923780) in one sample. Both SNVs were deposited as germline ones with uncertain clinical significance and phenotype. In one sample, we detected mutation NM_005896: c.394C > T, p.(Arg132Cys) (chr2:209, 113,113, rs121913499), which is indicated in ClinVar as a somatic pathogenic/likely pathogenic variant detected in many tumor types. The found mutations change the protein structure.

The frequency of $I D H 1$ mutations in PCC/PGLs is low. In paragangliomas, a mutation in IDH1 was first recorded during the analysis of 365 samples [31]. Somatic mutation in this gene was detected in carotid paraganglioma, although no IDH mutations were found in pheochromocytoma. According to the data of TCGA consortium, only one IDH1 somatic mutation was identified among 173 samples in codon 132. However, it can be explained by the fact that head and neck paragangliomas were not included in the final TCGA cohort. In another study, the analysis of 104 PCC/PGLs did not reveal any mutation in $I D H 1$ and $I D H 2$ genes [32]. Therefore, we can suggest that frequency of IDH1 mutations may be associated with localization of paragangliomas.

\section{ARNT}

Gene $A R N T$ encodes protein that is involved in activation of the xenobiotic metabolism genes [33]. This protein is also a cofactor for regulation of $H I F 1 A$ transcription.

We found a rare (0.0074) variant NM_001668: c.1551 T > G, p.(Asp517Glu) (chr1:150,789,864, rs1030 5741) of $A R N T$ gene in two samples. Data from ClinVar resources are absent. In Uniport database, it does not change any physical and chemical properties of protein. c. $1551 \mathrm{~T}>\mathrm{G}$ may be non-pathogenic mutation according to SIFT database.

We found mutation NM_001668: c.2335C > G, p.(Pro779Ala) (chr1:150,784,532, rs200078254) in one sample. This mutation is described in Ensembl and dbSNP databases as non-pathogenic one that is also supported by SIFT resource. The Cosmic database describes another mutation in the same codon (c.2335C > T, p. non-pathogenic (Pro779Ser)) in lung squamous cell carcinoma. According to FATHMM, it might be pathogenic mutation. However, in the case of Pro779Ser, the charge of the amino acid residue is changing in contrast to Pro779Ala.

We identified mutation NM_001668: c.1879C $>$ T, p.(Arg627Cys) (chr1:150,788,806) in one sample. According to examined databases, it is a rare mutation with unknown clinical effect, but it might be highly pathogenic one according to SIFT resource.

\section{TP53BP1}

Gene TP53BP1 encodes tumor suppressor p53-binding protein 1, also known as p53BP1 [34, 35]. Unstable expression of TP53BP1 is associated with genomic instability in oncocytic follicular adenoma of thyroid [36]. It plays a key role in DNA damage response, may have a role in checkpoint signaling during mitosis, and enhances TP53-mediated transcriptional activation. It was demonstrated that TP53BP1 is downregulated in most cases of triple-negative breast cancer [37].

In one sample, we found non-pathogenic missense mutation NM_005657: c.5242C > T, p.(Arg1748Cys) $($ chr15:43,705,365, rs140689367) $\quad($ SIFT $=0.13)$, highest population MAF $<0.01$ described in Ensembl database. In two samples, we found NM_005657: c.880 T > C, p.(Ser294Pro) (chr15:43,769,851, rs61751060) nonpathogenic missense mutation $(\mathrm{SIFT}=0.36)$ with global MAF of 0.003 described in Ensembl database.

\section{TP53BP2}

Gene TP53BP2 encodes tumor suppressor p53-binding protein 2 (p53BP2) [38-40]. p53BP2 plays an important role in regulation of apoptosis and cell growth [41]. p53BP2 binds to wild-type p53 but not to mutant one, suggesting that p53BP2 may be involved in the ability of p53 to suppress oncogenic transformation. TP53BP2 mRNA expression is frequently downregulated in human breast cancer [42]. Four single nucleotide polymorphisms in TP53BP2 are significantly correlated with gastric cancer susceptibility [43]. In general, patients with high TP53BP2 expression tend to have a longer median survival time than those with low TP53BP2 expression [44].

In one sample, we identified mutation NM_005426: c.2932C > T, p.(Arg978Cys) (chr1:223,971,861, rs1995 72474) described in Ensembl database. Its clinical significance is unknown by SIFT and PolyPhen- 2 resources. In another sample, we found mutation NM_005426: c.179C > T, p.(Ala60Val) (chr1:223,991,959, rs61749337) described in dbSNP and Ensembl databases. The mutation is pathogenic one by MutationTaster, LRT, and PolyPhen-2 predictions (MutationTaster score $=1.0$, LRT prediction $=$ 'Disease', and PolyPhen-2 score $=0.94$ ), but it has not been described in literature (Global MAF <0.003). In one sample, we found mutation NM_005426: c.1515G > C, p.(Gln505His) (chr1:223,985,963, rs61824007) described in dbSNP and Ensembl databases. This mutation is pathogenic one by PolyPhen-2 resource (0.993), but it is tolerant by SIFT (Global MAF $=0.003)$.

\section{TP53113}

Gene TP53I13 encodes tumor protein p53 inducible protein 13 that may act as a tumor suppressor, because it inhibits tumor cell growth when overexpressed. It can be upregulated by genotoxic stresses of adriamycin and/or UV irradiation in a p53/TP53-dependent manner [45].

In two samples, we found somatic missense mutation NM_138349: c.148C > G, p. (Pro50Ala) (chr17:27,896,342, 
rs112563021) with allele frequency 0.005810, MAF $<0.01(\mathrm{G})$.

\section{RET}

Protein RET constitutes a transmembrane tyrosine kinase receptor for extracellular signaling molecules of the GDNF family. It is required for development of the sympathetic, parasympathetic, as well as enteric nervous systems [46]. Germline and somatic mutations occur in gene RET with similar frequency (approximately 5-6\%) [10, 47].

We identified two samples with RET mutations. In both cases, it was NM_020630: c.2372A > T, p.(Tyr791Phe) (chr10:43,613,908, rs77724903) located in exon 13 and changing protein structure. This mutation is described both as germline and somatic one. Some data indicates that $R E T$ c.2372A $>\mathrm{T}$ is associated with familial medullary thyroid carcinoma (FMTC), hereditary cancer-predisposing syndrome, Hirschsprung disease, multiple endocrine neoplasia (MEN) including types 1, 2a, 2b, and 4, pheochromocytoma, and renal adysplasia [4, 48, 49].

It was observed in the work of TCGA consortium that $R E T$ mutations occurred in distinct protein coding regions with germline mutations clustered at codon 634 in the extracellular domain and somatic mutations clustered at codon 918 in the intracellular tyrosine kinase domain in PCC/PGLs [10]. In addition, a similar pattern was demonstrated for medullary thyroid carcinoma [50]. Mutation c.2372A $>\mathrm{T}$ is also located in tyrosine kinase domain, but it is deposited in ClinVar database several times as both germline and somatic one.

\section{KIF1B}

The KIF1B gene consists of 50 exons and encodes two protein isoforms, KIF1B $\alpha$ and KIF1B $\beta$. These proteins are involved in anterograde transport of mitochondria (KIF1B $\alpha)$ and synaptic vesicle precursors (KIF1B $\beta)$ [51, 52]. In addition, KIF1B $\beta$ was shown to represent a target of PHD3 protein and is involved in apoptosis. Missense mutations in the KIF1B gene were found for the first time in two PCC samples in 2008 [53]. Later, a group of relatives was found that increased probability of developing not only PCC, but also neuroblastomas, ganglioneuromas, and lung tumors for germline mutations in the KIF1B gene [54]. No mutations in the KIF1B gene have been detected in PGLs. In this work, we identified two KIF1B mutations NM_015074: c.4717C > T, p.(Pro1573Ser) (chr1:10,431,229) and NM_015074: c.1579G > C, p.(Gly527Arg) (chr1:10,355,764).

Both germline and somatic mutations in KIF1B gene have been found in pheochromocytoma, occasionally occurring in combinations with mutations in other genes, such as NF1, RET, VHL, and $S D H x[54,55]$. In our PGL cohort, one of two samples also has additional PDM in $B A P 1$ gene.

\section{CDKN2A}

The CDKN2A gene is located on the long arm of chromosome 9 at position 21.3, and encodes several proteins. The most well-studied proteins are p16 (INK4a) and p14 (ARF). Both proteins act as tumor suppressors. p16 protein in complex with CDK4 and CDK6 provides cell cycle regulation. $\mathrm{p} 14$ protein protects $\mathrm{p} 53$ and, therefore, can prevent malignization. CDKN2A gene is frequently mutated in head and neck squamous cell carcinomas.

In one sample, we identified mutation NM_058197: c.187G > C, p.(Gly63Arg) (chr9:21,974,640, rs45456595). According to ClinVar, this germline mutation has a conflicting clinical significance of pathogenicity. The occurrence frequency of c.187G > C mutation is 0.001 .

\section{BRAF}

Protein BRAF belongs to the family of RAF serine/threonine kinases and participates in activation of the RAS/ RAF/ERK signaling pathway [56]. Mutations in BRAF gene were initially identified in cancer types that are commonly associated with mutations in different isoforms of RAS, such as malignant melanoma and welldifferentiated thyroid cancer.

We identified only one sample with a non-canonical BRAF mutation NM_00433: c.533G > A, p.(Arg178Gln) (chr7:140,508,767, rs746348396), which changes protein structure. It has been deposited in ClinVar only once as the germline mutation with uncertain clinical significance in patient with "rasopathy" phenotype. In TCGA dataset of PGLs and PCC, only one somatic BRAF p.(G469A) SNV and also one fusion involving $B R A F$ was identified [10]. A common activating mutation in BRAF p.(V600E) has been recently found in one of 60 analyzed samples of PCC [57].

\section{$B R C A 1$ and $B R C A 2$}

These genes play an important role in DNA repair, cell cycle checkpoint regulation, and genome stability maintenance [58]. Germline mutations in these genes are associated with hereditary breast and ovarian cancers [59], Fallopian tube, prostate, peritoneal, and pancreatic cancers [60]. Germline mutations in BRCA genes were demonstrated for two patients with PCC [61].

PDM NM_003000: c.5019G > A, p.(Met1673Ile) (chr17:41,222,975, rs1799967) was identified in BRCA1 gene. According to ClinVar, this mutation is nonpathogenic one. Frequency of occurrence of this mutation based on ExAC dataset is 0.0176 .

In one sample, a rare mutation NM_000059: c.4585G > A, p.(Gly1529Arg) (chr13:32,913,077, rs28897728) was evaluated in BRCA2 gene. Despite the low frequency in population (0.0004, according to ExAC), it is considered to be non-pathogenic mutation based on different investigations. 


\section{CSDE1}

Gene CSDE1 (cold shock domain containing E1) encodes a RNA-binding protein. It is required for internal initiation of translation of human rhinovirus RNA. It may be also involved in translationally coupled mRNA turnover. In this gene, we identified a mutation NM_007158: c.416C > T, p.(Ala139Val) (chr1:115,277,136, rs151170620). This mutation with unknown clinical significance was not described previously. It is predicted to be pathogenic mutation by resources such as PolyPhen-2, MutationTaster, and LRT. Besides, it is a rare mutation and its frequency of occurrence in population of healthy people is 0.0001 .

\section{BAP1}

BAP1 represents an onco-suppressor that participates in the regulation of the cell cycle, differentiation, gluconeogenesis, and DNA damage response [62]. Germline mutations in the BAP1 are associated with increased risks of malignant mesothelioma as well as uveal and cutaneous melanoma, whereas somatic mutations in this gene have been detected in various types of tumors including PGLs [63, 64].

We identified BAP1 mutation NM_004656: c.1135G > A, p.(Ala379Thr) (chr3:52,438,584) in a sample. It is not represented in dbSNP, ClinVar, and Ensembl databases, but it may be pathogenic mutation based on SIFT, PolyPhen-2, LRT, and MutationTaster algorithms. Moreover, it is located in a highly conservative DNA region (phastCons resource data), and it does not occur in population of healthy people (ExAc and 1000 Genomes project data).

\section{MEN1}

The MEN1 gene encodes the menin protein, which is localized in the nucleus and interacts with different proteins involved in transcription regulation, genome stabilization, cell division, and proliferation $[65,66]$. Germline mutations in the MEN1 gene may lead to multiple endocrine neoplasia type 1 (MEN1 syndrome), and be associated with the development of over 20 types of endocrine and non-endocrine tumors including PCC and PGLs [67-70].

Mutation NM_130799: c.512G > A, p.(Arg171Gln) (chr11:64,575,505, rs607969) was determined in one sample. In ClinVar database, it is deposited as germline mutation with unknown pathogenic significance [71]. In Cosmic database, this mutation is described as germinal one in the heterozygous state in adrenal cortical carcinoma [72] and as somatic one in hemangioblastoma [73] and prostate carcinoma. According to SIFT, MutationTaster, and FATHMM, it is pathogenic mutation. Although mutations in MEN1 gene are rare, they represent important objects of screening as they provide the means of early diagnostics of MEN1 syndrome [74].
SETD2

The SETD2 protein is a histone methyltransferase that is specific for lysine-36 histone H3, and methylation of this residue is associated with chromatin activation. This protein also contains a transcriptional activation domain associated with hyperphosphorylated RNA polymerase II.

We found PDM NM_014159: c.3229A > G, p.(Thr10 77Ala) (chr3:47,162,897, rs114719990) in one CBT sample. It was described as germline mutation in the article dedicated to genes of predisposition to malignancy, data is available in ClinVar. Unfortunately, there are no data about the clinical effect of this mutation [75]. Based on SIFT, MutationTaster, LRT, and PolyPhen-2 algorithms, c.3229A > G might be highly pathogenic mutation.

\section{FGFR3}

This gene encodes a member of the fibroblast growth factor receptor (FGFR) family, and its amino acid sequence is highly conserved. The extracellular part of the protein interacts with fibroblast growth factors driving a cascade of downstream signals, ultimately affecting mitogenesis and differentiation. FGFR3 binds the acidic and basic fibroblast growth hormone and plays a role in the development and maintenance of bone tissue. Mutations in this gene lead to craniosynostosis and multiple types of skeletal dysplasia. Three variants of transcripts, that encode different isoforms of the protein, are described.

We evaluated PDM NM_000142:c.1150 T > C, p.(Phe384Leu) (chr4:1,806,131, rs17881656) in one sample. Mutation $1156 \mathrm{~T}>\mathrm{C}$ was described as germline one with unknown clinical significance [75]. Based on data of several researchers (ClinVar) as well as on SIFT, the prediction is that this mutation is probably non-pathogenic one.

\section{Mutation load}

Mutation load was estimated for all samples (Fig. 5, Additional file 4). The average ML was 6-8 potentially somatic deleterious mutations per megabase and varied from 2 to 10.5 mutations. Moreover, the most mutated genes were identified (Fig. 6, Additional file 5). Top 50 genes with the highest somatic mutation number are represented in Fig. 6, but only 20 genes have a very high amount of mutations and then the curve plateaus. This list includes ZNF717, CDC27, FRG2C, FAM104B, CTBP2, HLA-DRB1, HYDIN, KMT5A, MUC3A, PRSS3, ANKRD36B, CTDSP2, KIR2DS4, FRG1, KRTAP4-6, MTCH2, BAGE4, OR2T35, GXYLT1, and $H L A-D R B 5$. Figure 7 illustrates that these genes, being highly mutated almost in all samples, are clustered and visualized in the lower part of the heatmap. The set of other highly mutated genes is different from sample to sample and seems to be specific for each tumor. 


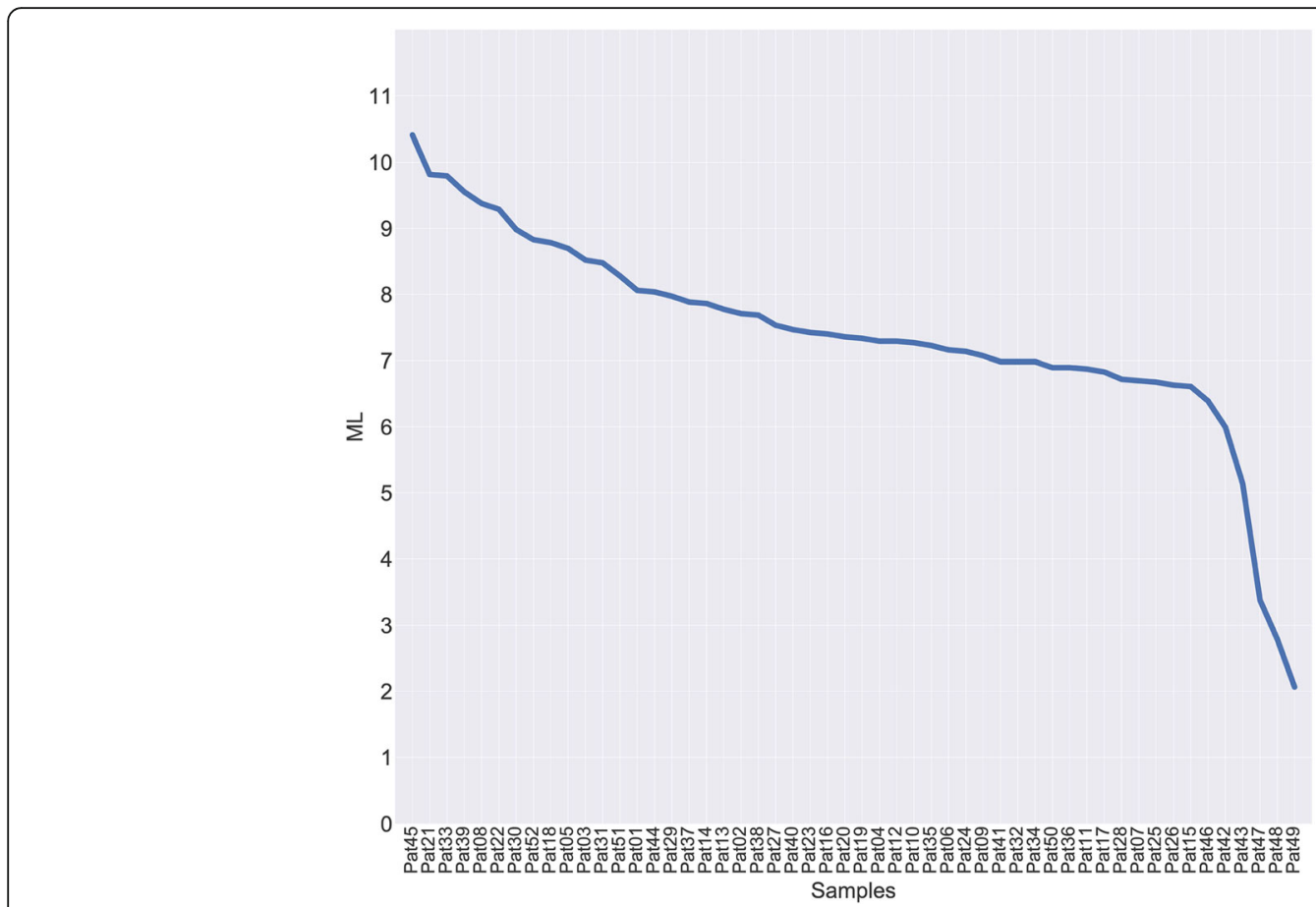

Fig. 5 Analysis of mutation load in carotid body tumor (CBT) samples. Distribution of potentially somatic deleterious mutations among the CBT samples was evaluated to estimate their number per megabase of coding regions

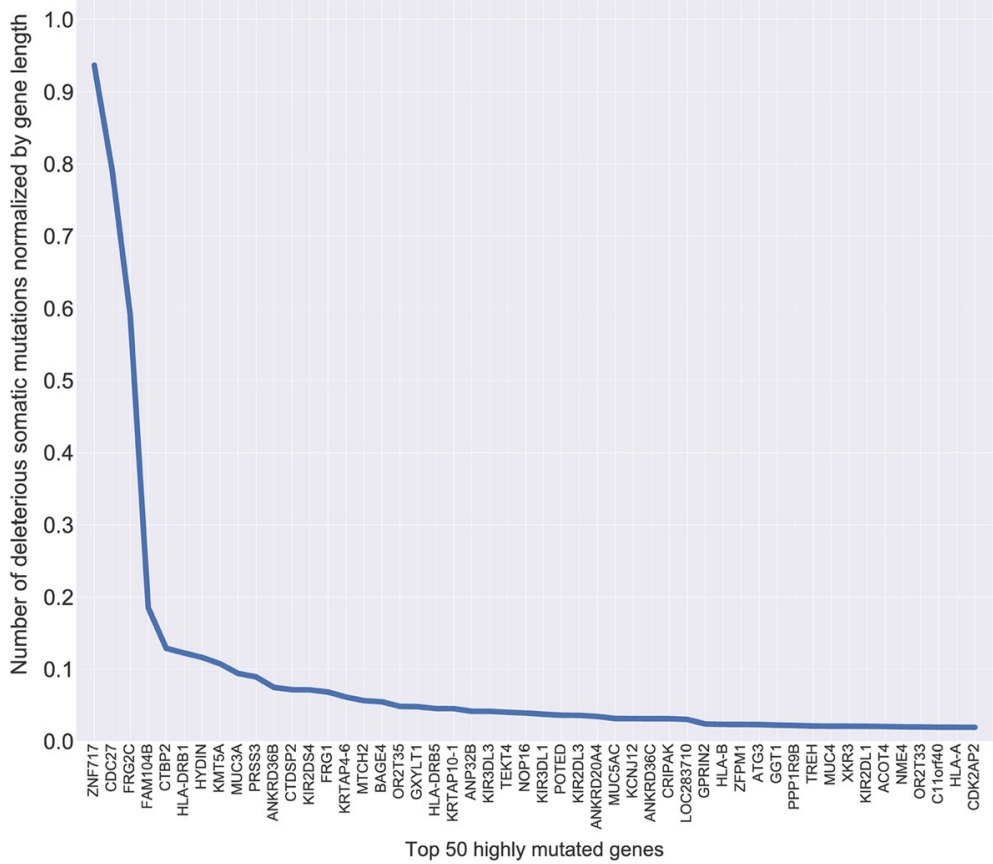

Fig. 6 List of top 50 most frequently mutated genes in CBTs. Number of potentially somatic deleterious mutations normalized by gene length for 52 samples in total is indicated by Y-axis 


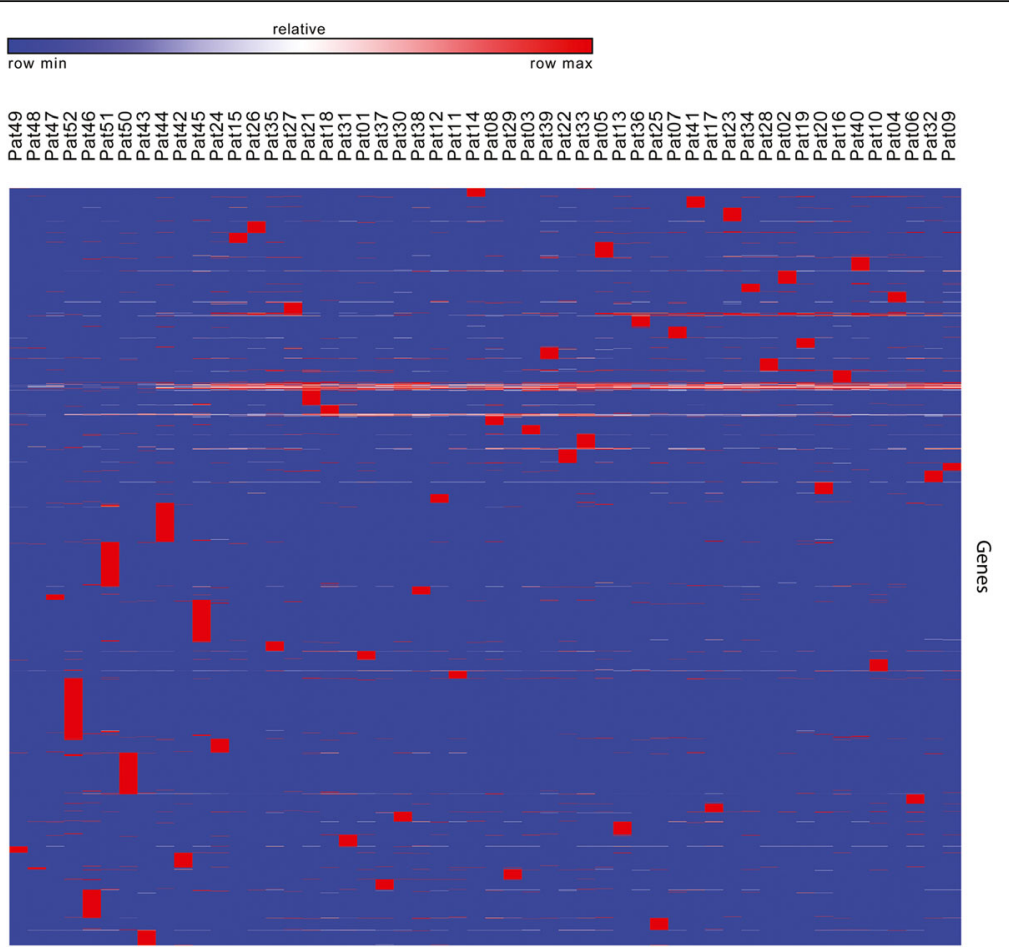

Fig. 7 Heatmap of potentially somatic deleterious mutations in CBTs normalized by gene length across all genes for all patients. Red color indicates highly mutated genes and blue color flags genes with low level of potentially somatic deleterious mutations

\section{Discussion}

Carotid body tumor is the most common form of HNPGLs (60-80\%), but it is not well investigated with different molecular methods, such as mRNA and miRNA analysis, as well as methylation profiling. The first reason is absence of normal matched tissue. The second one is the requirement for embolization of tumors before surgical treatment [76]. Necrotic tissue forms after this procedure, and mutational tests became the only possible molecular analysis. Thus, TCGA consortium excluded CBTs from PGLs/PCC analysis due to inability for comprehensive approach to this type of tumor, and the reliable mutation frequency for all patients with CBT is unknown [10]. Commonly, only the cohorts with familial history or the cohorts with multiple tumors, as well as with metastatic cases are included in mutational analysis [77]. It provides incorrect data on frequency of mutations in different genes across all CBT cases. For example, regarding molecular genetics, head and neck paragangliomas have been associated with nine susceptibility genes NF1, RET, VHL, SDHA, SDHB, SDHC, SDHD, SDHAF2 (SDH5), and TMEM127 [77]. Inherited HNPGLs are mostly caused by mutations in $S D H D$, $S D H B$, and $S D H C$ genes. HNPGLs are rarely associated with mutations of $V H L, R E T$, and NF1. In addition, it was shown that multiple HNPGLs are common in patients with $S D H D$ mutations, while malignant head and neck paragangliomas are mostly seen in patients with $S D H B$ mutations [77]. Thus, it was demonstrated that the penetrance for $S D H D$ germline mutations is about twice as high as that of $S D H B$ carriers. SDHD mutations induced HNPGLs about 20 years earlier compared with $S D H B$ mutations [78]. And only correlation of germline $S D H B$ mutations with tumor aggressiveness is indicated as an established fact.

For the first time exome analysis for representative cohort of 52 carotid paragangliomas, collected from the single origin (carotid body) and consisting of patients with familial and sporadic forms, was performed hereby. The frequencies of PDMs in different cancer-associated genes and mutation load were determined in CBTs from Russian patients. According to our results, the frequency of mutations in the main causative genes is different from the other investigations $[10,79]$. The most common gene with PDMs was $S D H D, 13.5 \%$ of the entire cohort (Table 1$)$. In total, $S D H x$ mutations span $26 \%$ of patients, but in some cases, $S D H x$ mutations co-occur with PDMs in other genes. Mutations in $S D H x$ genes increase the stability of HIFs and, thus, the expression of their targets through the intracellular accumulation of their substrate, succinate. It could determine pseudohypoxic phenotype potentially resulting in energy metabolism changes and correlate with aggressive phenotype, and it requires different management $[47,80,81]$. 
We did not identify mutations in NF1, VHL, MEN1, SDHAF2, and TMEM127 genes, which are indicated in many papers as causative for carotid PGLs. Differences in frequency could be elucidated either by population specificity or inclusion of PGLs from different origins as well as even PCC in this cohort and their simultaneous analysis. One more reason might be the difference in filtration methods for evaluation of potentially pathogenic mutations. Future investigations will allow standardizing this procedure after depositing new mutations in databases and experimental estimation of their pathogenic effect.

In $27 \%$ of CBT samples, more than one potential driver mutation was observed. In two samples, two PDMs were observed in the same gene (SDHC and TP53BP2). It is possible that one mutation is not always enough for oncogenic cell transformation. In some cases, it could probably be explained by tumor heterogeneity. We did not identify PDMs in $44 \%$ of tumors using sufficiently strong settings for filtration. We suggest that two or more non-highly pathogenic mutations demonstrate cumulative effect and can cause tumor growth in many cases. It is critically important to be concentrated on the PDMs in other genes, which were not described before as PGLs/PCC causative.

The prevalence of somatic mutations was demonstrated to be highly variable between and within cancers, ranging from about $0.001 / \mathrm{Mb}$ to more than $400 / \mathrm{Mb}$. The lowest ML was observed in pilocytic astrocytoma and the highest one - for malignant melanoma, lung, and bladder cancer [12]. In CBTs, we revealed ML of approximately 6-8 mutations per megabase. Although, we cannot compare our data directly with the result published in [15] because of different methods for somatic mutation identification. In mentioned paper, normal DNA from the same individuals was sequenced to establish the somatic origin of variants [12]. We used samples collected since year 1990, and in most cases the non-tumor tissues were unavailable. Thus, the computational methods for potentially germline mutation exclusion were used. Algorithms for filtration based on frequency of mutations in healthy individuals (1000 Genomes project) have been shown to exclude more than $96 \%$ of germline mutations [82]. We used additional database and applied more stringent requirements for filtration. The only variants established as somatic mutations were the ones nonexistent in populations of healthy individuals according to the ExAC database and 1000 Genomes data. We considered only deleterious variants (i.e., frameshift or nonsynonymous coding variants) for further analysis of ML. In order to estimate ML across all patients, we have normalized the number of potentially somatic deleterious mutations per megabase of coding region. The coding region length was $45,540,944$ base pairs. To identify the most mutated genes, we divided the number of potentially somatic deleterious mutations by the length of gene coding region (gene length).
Therefore, using this type of analysis allows comparing samples within cohort to distinguish hypermutated samples. Recently, a close relationship between ML and response to checkpoint immunotherapy was demonstrated for several cancer types [83-85]. In highly mutated samples, a number of neoantigens become visible to the immune system, creating the basis for effective $\mathrm{T}$ cell responses. Checkpoint inhibitors, such as ipilimumab, nivolumab, and pembrolizumab, have provided a breakthrough in cancer immunotherapy including treatment of melanoma, colorectal, and lung cancers [86]. Immunotherapy will probably be a promising approach for treatment of carotid paragangliomas with high ML, especially for aggressive and metastatic tumors.

\section{Conclusions}

Exome analysis of CBTs revealed the average mutation load for these tumors, identified potentially driver mutations as well as their frequencies and co-occurrence with other PDMs. Several novel undescribed mutations were identified. Evaluation of driver mutations leading to tumor growth, progression, and differences in clinicopathologic characteristics, as well as identification of highly mutated samples provide opportunities to develop new approaches for targeted therapy and immunotherapy of the disease, and increase the management level of CBTs.

\section{Additional files}

Additional file 1: High impact mutation types included in the analysis. (XLSX $9 \mathrm{~kb}$ )

Additional file 2: Pathways and conditions associated with the selected genes. (XLSX $57 \mathrm{~kb}$ )

Additional file 3: List of evaluated potentially driver mutations and their detailed description. (XLSX $22 \mathrm{~kb}$ )

Additional file 4: Mutation load (ML) - number of computationally filtered deleterious somatic mutations per megabase of coding region across all samples. (XLSX $48 \mathrm{~kb}$ )

Additional file 5: Total number of deleterious somatic mutations normalized by gene length in 52 CBT samples. (XLSX $132 \mathrm{~kb}$ )

\section{Abbreviations}

CBT: Carotid body tumor; HNPGLs: Head and neck paragangliomas; ML: Mutation load; PCC: Pheochromocytoma; PDM: Potential driver mutation; PGLs: Paragangliomas; SDHX: Genes encoding components of succinate-dehydrogenase complex. In this work: SDHA, SDHB, SDHC, SDHD, SDHAF1, and SDHAF2

\section{Acknowledgements}

Authors thank Vishnevsky Institute of Surgery for supplying samples; National Medical Research Radiological Center, Vavilov Institute of General Genetics, and Pirogov Russian National Research Medical University for the assistance in computational analysis; Initium-Pharm, LTD for providing computational resources.

This work was performed using the equipment of EIMB RAS "Genome" center (http://www.eimb.ru/rus/ckp/ccu_genome_c.php). 


\section{Funding}

This work and publication costs were funded by the Russian Science Foundation, grant 17-75-20105.

\section{Availability of data and materials}

All data generated or analyzed during this study are included in this published article and its supplementary information files. The sequencing data are available through the NCBI Sequence Read Archive (project ID: PRJNA411769).

\section{About this supplement}

This article has been published as part of BMC Medical Genomics Volume 11 Supplement 1, 2018: Selected articles from Belyaev Conference 2017: medical genomics. The full contents of the supplement are available online at https://bmcmedgenomics.biomedcentral.com/articles/supplements/ volume-11-supplement-1.

\section{Authors' contributions}

ENL, AVS, and AVK conceived and designed the work; AVS, AVK, NVK, EAP, MSF, NNV, OAS, EAZ, SLK, AVL, ISA, YEY, KSV, NVM, and DSS performed the experiments; ENL, GSK, DVK, AAD, AVG, AAM, GSK, MVK, AAD, BYA, ARZ and AVK analyzed the data; AVK, ENL, AVP, and BYA wrote the manuscript. All authors read and approved the final manuscript.

\section{Ethics approval and consent to participate}

The study was approved by The Ethics committee of A.V. Vishnevsky Institute of Surgery, Ministry of Health of the Russian Federation. The study was done in accordance with the principles outlined in the Declaration of Helsinki (1964).

\section{Consent for publication}

Not applicable.

\section{Competing interests}

The authors declare that they have no competing interests.

\section{Publisher's Note}

Springer Nature remains neutral with regard to jurisdictional claims in published maps and institutional affiliations.

\section{Author details}

${ }^{1}$ Engelhardt Institute of Molecular Biology, Russian Academy of Sciences, Moscow, Russia. ${ }^{2}$ Vishnevsky Institute of Surgery, Ministry of Health of the Russian Federation, Moscow, Russia. ${ }^{3}$ National Medical Research Radiological Center, Ministry of Health of the Russian Federation, Moscow, Russia.

${ }^{4}$ Pirogov Russian National Research Medical University, Moscow, Russia.

\section{Published: 13 February 2018}

\section{References}

1. Amato B, Bianco T, Compagna R, Siano M, Esposito G, Buffone G, Serra R, de Franciscis S. Surgical resection of carotid body paragangliomas: 10 years of experience. Am J Surg. 2014;207(2):293-8.

2. Zhikrivetskaya SO, Snezhkina AV, Zaretsky AR, Alekseev BY, Pokrovsky AV, Golovyuk AL, Melnikova NV, Stepanov OA, Kalinin DV, Moskalev AA, et al. Molecular markers of paragangliomas/pheochromocytomas. Oncotarget. 2017;8(15):25756-82.

3. Gimenez-Roqueplo AP, Dahia PL, Robledo M. An update on the genetics of paraganglioma, pheochromocytoma, and associated hereditary syndromes. Horm Metab Res. 2012;44(5):328-33.

4. Neumann HP, Bausch B, McWhinney SR, Bender BU, Gimm O, Franke G, Schipper J, Klisch J, Altehoefer C, Zerres K, et al. Germ-line mutations in nonsyndromic pheochromocytoma. N Engl J Med. 2002:346(19):1459-66.

5. Baysal BE, Ferrell RE, Willett-Brozick JE, Lawrence EC, Myssiorek D, Bosch A, van der Mey A, Taschner PE, Rubinstein WS, Myers EN, et al. Mutations in $\mathrm{SDHD}$, a mitochondrial complex II gene, in hereditary paraganglioma. Science. 2000;287(5454):848-51

6. Burnichon N, Buffet A, Parfait B, Letouze E, Laurendeau I, Loriot C, Pasmant E, Abermil N, Valeyrie-Allanore L, Bertherat J, et al. Somatic NF1 inactivation is a frequent event in sporadic pheochromocytoma. Hum Mol Genet. 2012; 21(26):5397-405.
7. Burnichon N, Cascon A, Schiavi F, Morales NP, Comino-Mendez I, Abermil N, Inglada-Perez L, de Cubas AA, Amar L, Barontini M, et al. MAX mutations cause hereditary and sporadic pheochromocytoma and paraganglioma. Clin Cancer Res. 2012;18(10):2828-37.

8. Welander J, Larsson C, Backdahl M, Hareni N, Sivler T, Brauckhoff M, Soderkvist P, Gimm O. Integrative genomics reveals frequent somatic NF1 mutations in sporadic pheochromocytomas. Hum Mol Genet. 2012;21(26):5406-16.

9. Toledo RA, Qin Y, Srikantan S, Morales NP, Li Q, Deng Y, Kim SW, Pereira MA, Toledo SP, Su X, et al. In vivo and in vitro oncogenic effects of HIF2A mutations in pheochromocytomas and paragangliomas. Endocr Relat Cancer. 2013:20(3):349-59.

10. Fishbein $L$, Leshchiner I, Walter $V$, Danilova $L$, Robertson $A G$, Johnson AR, Lichtenberg TM, Murray BA, Ghayee HK, Else T, et al. Comprehensive molecular characterization of Pheochromocytoma and Paraganglioma. Cancer Cell. 2017:31(2):181-93.

11. Babic B, Patel D, Aufforth R, Assadipour Y, Sadowski SM, Quezado M, Nilubol N, Prodanov T, Pacak K, Kebebew E. Pediatric patients with pheochromocytoma and paraganglioma should have routine preoperative genetic testing for common susceptibility genes in addition to imaging to detect extra-adrenal and metastatic tumors. Surgery. 2017;161(1):220-7.

12. Stratton MR, Campbell PJ, Futreal PA. The cancer genome. Nature. 2009; 458(7239):719-24

13. Pfeifer GP. Environmental exposures and mutational patterns of cancer genomes. Genome Med. 2010;2(8):54.

14. Pena-Diaz J, Bregenhorn S, Ghodgaonkar M, Follonier C, Artola-Boran M, Castor D, Lopes M, Sartori AA, Jiricny J. Noncanonical mismatch repair as a source of genomic instability in human cells. Mol Cell. 2012;47(5):669-80.

15. Alexandrov LB, Nik-Zainal S, Wedge DC, Aparicio SA, Behjati S, Biankin AV, Bignell GR, Bolli N, Borg A, Borresen-Dale AL, et al. Signatures of mutational processes in human cancer. Nature. 2013:500(7463):415-21.

16. Sinnadurai $M, M c D o n a l d ~ K L$. Immune checkpoint inhibition and its relationship with hypermutation phenoytype as a potential treatment for Glioblastoma. J Neuro-Oncol. 2017;132(3):359-72.

17. Ponce RA, Gelzleichter T, Haggerty HG, Heidel S, Holdren MS, Lebrec $H$, Mellon RD, Pallardy M. Immunomodulation and lymphoma in humans. J Immunotoxicol. 2014:11(1):1-12.

18. Castro MP, Goldstein N. Mismatch repair deficiency associated with complete remission to combination programmed cell death ligand immune therapy in a patient with sporadic urothelial carcinoma: immunotheranostic considerations. J Immunother Cancer. 2015;3:58.

19. Gargiulo P, Della Pepa C, Berardi S, Califano D, Scala S, Buonaguro L, Ciliberto G, Brauchli P, Pignata S. Tumor genotype and immune microenvironment in POLE-ultramutated and MSI-hypermutated endometrial cancers: new candidates for checkpoint blockade immunotherapy? Cancer Treat Rev. 2016;48:61-8.

20. Rustin $P$, Rotig A. Inborn errors of complex II-unusual human mitochondria diseases. Biochim Biophys Acta. 2002;1553(1-2):117-22.

21. Yankovskaya V, Horsefield R, Tornroth S, Luna-Chavez C, Miyoshi H, Leger C, Byrne B, Cecchini G, Iwata S. Architecture of succinate dehydrogenase and reactive oxygen species generation. Science. 2003;299(5607):700-4.

22. Ghezzi D, Goffrini P, Uziel G, Horvath R, Klopstock T, Lochmuller H, D'Adamo P, Gasparini P, Strom TM, Prokisch H, et al. SDHAF1, encoding a LYR complex-II specific assembly factor, is mutated in SDH-defective infantile leukoencephalopathy. Nat Genet. 2009;41(6):654-6.

23. Hao HX, Khalimonchuk O, Schraders M, Dephoure N, Bayley JP, Kunst $H$, Devilee P, Cremers CW, Schiffman JD, Bentz BG, et al. SDH5, a gene required for flavination of succinate dehydrogenase, is mutated in paraganglioma. Science. 2009;325(5944):1139-42.

24. Castelblanco E, Santacana M, Valls J, de Cubas A, Cascon A, Robledo M, Matias-Guiu X. Usefulness of negative and weak-diffuse pattern of SDHB immunostaining in assessment of SDH mutations in paragangliomas and pheochromocytomas. Endocr Pathol. 2013;24(4):199-205.

25. Timmers HJ, Kozupa A, Eisenhofer G, Raygada M, Adams KT, Solis D, Lenders JW, Pacak K. Clinical presentations, biochemical phenotypes, and genotypephenotype correlations in patients with succinate dehydrogenase subunit B-associated pheochromocytomas and paragangliomas. J Clin Endocrinol Metab. 2007;92(3):779-86.

26. Choat H, Derrevere K, Knight L, Brown W, Mack EH. SDHB-associated Paraganglioma in a pediatric patient and literature review on hereditary Pheochromocytoma-Paraganglioma syndromes. Case Rep Endocrinol. 2014; 2014:502734. 
27. Helman G, Caldovic L, Whitehead MT, Simons C, Brockmann K, Edvardson S, Bai R, Moroni I, Taylor JM, Van Haren K, et al. Magnetic resonance imaging spectrum of succinate dehydrogenase-related infantile leukoencephalopathy. Ann Neurol. 2016;79(3):379-86.

28. Ricketts CJ, Shuch B, Vocke CD, Metwalli AR, Bratslavsky G, Middelton L, Yang $Y$, Wei $\mathrm{MH}$, Pautler SE, Peterson J, et al. Succinate dehydrogenase kidney cancer: an aggressive example of the Warburg effect in cancer. J Urol. 2012;188(6):2063-71.

29. Jackson CB, Nuoffer JM, Hahn D, Prokisch H, Haberberger B, Gautschi M, Haberli A, Gallati S, Schaller A. Mutations in SDHD lead to autosomal recessive encephalomyopathy and isolated mitochondrial complex II deficiency. J Med Genet. 2014;51(3):170-5.

30. Gaal J, Burnichon N, Korpershoek E, Roncelin I, Bertherat J, Plouin PF, de Krijger RR, Gimenez-Roqueplo AP, Dinjens WN. Isocitrate dehydrogenase mutations are rare in pheochromocytomas and paragangliomas. J Clin Endocrinol Metab. 2010;95(3):1274-8.

31. Gaal J, Burnichon N, Korpershoek E, Roncelin I, Bertherat J, Plouin PF, de Krijger RR, Gimenez-Roqueplo AP, Dinjens WN. Isocitrate dehydrogenase mutations are rare in pheochromocytomas and paragangliomas. J Clin Endocrinol Metab. 2010;95(3):1274-8.

32. Yao L, Schiavi F, Cascon A, Qin Y, Inglada-Perez L, King EE, Toledo RA, Ercolino T, Rapizzi E, Ricketts CJ, et al. Spectrum and prevalence of FP/ TMEM127 gene mutations in pheochromocytomas and paragangliomas. JAMA. 2010;304(23):2611-9.

33. Huang CR, Lee CT, Chang KY, Chang WC, Liu YW, Lee JC, Chen BK. Downregulation of ARNT promotes cancer metastasis by activating the fibronectin/integrin beta1/FAK axis. Oncotarget. 2015;6(13):11530-46.

34. Iwabuchi K, Bartel PL, Li B, Marraccino R, Fields S. Two cellular proteins that bind to wild-type but not mutant p53. Proc Natl Acad Sci U S A. 1994; 91(13):6098-102.

35 Iwabuchi K, Li B, Massa HF, Trask BJ, Date T, Fields S. Stimulation of p53mediated transcriptional activation by the p53-binding proteins, 53BP1 and 53BP2. J Biol Chem. 1998;273(40):26061-8.

36. Mussazhanova Z, Akazawa Y, Matsuda K, Shichijo K, Miura S, Otsubo R, Oikawa M, Yoshiura K, Mitsutake N, Rogounovitch T, et al. Association between p53-binding protein 1 expression and genomic instability in oncocytic follicular adenoma of the thyroid. Endocr J. 2016;63(5):457-67.

37. Bouwman P, Aly A, Escandell JM, Pieterse M, Bartkova J, van der Gulden $H_{\text {, }}$ Hiddingh S, Thanasoula M, Kulkarni A, Yang Q, et al. 53BP1 loss rescues BRCA1 deficiency and is associated with triple-negative and BRCA-mutated breast cancers. Nat Struct Mol Biol. 2010;17(6):688-95.

38. Gorina S, Pavletich NP. Structure of the p53 tumor suppressor bound to the ankyrin and SH3 domains of 53BP2. Science. 1996;274(5289):1001-5.

39. Pirozzi G, McConnell SJ, Uveges AJ, Carter JM, Sparks AB, Kay BK, Fowlkes DM. Identification of novel human WW domain-containing proteins by cloning of ligand targets. J Biol Chem. 1997;272(23):14611-6.

40. Yang JP, Ono T, Sonta S, Kawabe T, Okamoto T. Assignment of p53 binding protein (TP53BP2) to human chromosome band $1 \mathrm{q} 42.1$ by in situ hybridization. Cytogenet Cell Genet. 1997;78(1):61-2.

41. Yang JP, Hori M, Takahashi N, Kawabe T, Kato H, Okamoto T. NF-kappaB subunit p65 binds to 53BP2 and inhibits cell death induced by 53BP2. Oncogene. 1999;18(37):5177-86.

42. Cobleigh MA, Tabesh B, Bitterman P, Baker J, Cronin M, Liu ML, Borchik R, Mosquera JM, Walker MG, Shak S. Tumor gene expression and prognosis in breast cancer patients with 10 or more positive lymph nodes. Clin Cancer Res. 2005;11(24 Pt 1):8623-31.

43. Ju H, Lee KA, Yang M, Kim HJ, Kang CP, Sohn TS, Rhee JC, Kang C, Kim JW TP53BP2 locus is associated with gastric cancer susceptibility. Int J Cancer. 2005;117(6):957-60.

44. Lossos IS, Natkunam Y, Levy R, Lopez CD. Apoptosis stimulating protein of p53 (ASPP2) expression differs in diffuse large B-cell and follicular center lymphoma: correlation with clinical outcome. Leuk Lymphoma. 2002:43(12):2309-17.

45. Hata T, Ogawa T, Yokoyama TA, Fukushige S, Horii A, Furukawa T. DSCP1, a novel TP53-inducible gene, is upregulated by strong genotoxic stresses and its overexpression inhibits tumor cell growth in vitro. Int J Oncol. 2004;24(3):513-20.

46. Ichihara M, Murakumo Y, Takahashi M. RET and neuroendocrine tumors. Cancer Lett. 2004;204(2):197-211

47. Jaakkola P, Mole DR, Tian YM, Wilson MI, Gielbert J, Gaskell SJ, von Kriegsheim A, Hebestreit HF, Mukherji M, Schofield CJ, et al. Targeting of HIF-alpha to the von Hippel-Lindau ubiquitylation complex by O2-regulated prolyl hydroxylation. Science. 2001;292(5516):468-72.
48. Freudenberg-Hua Y, Freudenberg J, Vacic V, Abhyankar A, Emde AK, BenAvraham D, Barzilai N, Oschwald D, Christen E, Koppel J, et al. Disease variants in genomes of 44 centenarians. Mol Genet Genomic Med. 2014;2(5):438-50.

49. Baumgartner-Parzer SM, Lang R, Wagner L, Heinze G, Niederle B, Kaserer K, WaldhausI W, Vierhapper H. Polymorphisms in exon 13 and intron 14 of the RET protooncogene: genetic modifiers of medullary thyroid carcinoma? J Clin Endocrinol Metab. 2005;90(11):6232-6.

50. Figlioli G, Kohler A, Chen B, Elisei R, Romei C, Cipollini M, Cristaudo A, Bambi F, Paolicchi E, Hoffmann P, et al. Novel genome-wide association studybased candidate loci for differentiated thyroid cancer risk. J Clin Endocrinol Metab. 2014;99(10):E2084-92.

51. Nangaku M, Sato-Yoshitake R, Okada Y, Noda Y, Takemura R, Yamazaki H, Hirokawa N. KIF1B, a novel microtubule plus end-directed monomeric motor protein for transport of mitochondria. Cell. 1994;79(7):1209-20.

52. Zhao C, Takita J, Tanaka Y, Setou M, Nakagawa T, Takeda S, Yang HW, Terada S, Nakata T, Takei Y, et al. Charcot-Marie-tooth disease type 2A caused by mutation in a microtubule motor KIF1Bbeta. Cell. 2001;105(5):587-97.

53. Schlisio S, Kenchappa RS, Vredeveld LC, George RE, Stewart R, Greulich H, Shahriari K, Nguyen NV, Pigny P, Dahia PL, et al. The kinesin KIF1Bbeta acts downstream from EgIN3 to induce apoptosis and is a potential 1p36 tumor suppressor. Genes Dev. 2008;22(7):884-93.

54. Yeh IT, Lenci RE, Qin Y, Buddavarapu K, Ligon AH, Leteurtre E, Do Cao C, Cardot-Bauters C, Pigny P, Dahia PL. A germline mutation of the KIF1B beta gene on 1 p36 in a family with neural and nonneural tumors. Hum Genet. 2008:124(3):279-85.

55. Welander J, Andreasson A, Juhlin CC, Wiseman RW, Backdahl M, Hoog A, Larsson C, Gimm O, Soderkvist P. Rare germline mutations identified by targeted next-generation sequencing of susceptibility genes in pheochromocytoma and paraganglioma. J Clin Endocrinol Metab. 2014; 99(7):E1352-60.

56. Hoeflich KP, Gray DC, Eby MT, Tien JY, Wong L, Bower J, Gogineni A, Zha J, Cole MJ, Stern HM, et al. Oncogenic BRAF is required for tumor growth and maintenance in melanoma models. Cancer Res. 2006;66(2):999-1006.

57. Luchetti A, Walsh D, Rodger F, Clark G, Martin T, Irving R, Sanna M, Yao M, Robledo M, Neumann HP, et al. Profiling of somatic mutations in phaeochromocytoma and paraganglioma by targeted next generation sequencing analysis. Int J Endocrinol. 2015;2015:138573.

58. Kinzler KW, Vogelstein B. Cancer-susceptibility genes. Gatekeepers and caretakers. Nature. 1997;386(6627):761. 763

59. Larsen MJ, Thomassen M, Gerdes AM, Kruse TA. Hereditary breast cancer: clinical, pathological and molecular characteristics. Breast Cancer (Auckl). 2014;8:145-55.

60. Mersch J, Jackson MA, Park M, Nebgen D, Peterson SK, Singletary C, Arun BK, Litton JK. Cancers associated with BRCA1 and BRCA2 mutations other than breast and ovarian. Cancer. 2015;121(2):269-75.

61. Barak F, Shiri-Svredlov R, Bruchim-Bar Sade R, Kruglikova A, Friedman E, BenDor D, Goldberg I. Adrenal tumors in BRCA1/BRCA2 mutation carriers. Am J Med Genet. 2001;98(3):277-9.

62. Carbone M, Yang H, Pass HI, Krausz T, Testa JR, Gaudino G. BAP1 and cancer. Nat Rev Cancer. 2013;13(3):153-9.

63. Murali R, Wiesner T, Scolyer RA. Tumours associated with BAP1 mutations. Pathology. 2013;45(2):116-26.

64. Wadt K, Choi J, Chung JY, Kiilgaard J, Heegaard S, Drzewiecki KT, Trent JM, Hewitt SM, Hayward NK, Gerdes AM, et al. A cryptic BAP1 splice mutation in a family with uveal and cutaneous melanoma, and paraganglioma. Pigment Cell Melanoma Res. 2012;25(6):815-8

65. Larsson C, Skogseid B, Oberg K, Nakamura Y, Nordenskjold M. Multiple endocrine neoplasia type 1 gene maps to chromosome 11 and is lost in insulinoma. Nature. 1988;332(6159):85-7.

66. Agarwal SK, Kester MB, Debelenko LV, Heppner C, Emmert-Buck MR, Skarulis MC, Doppman JL, Kim YS, Lubensky IA, Zhuang Z, et al. Germline mutations of the MEN1 gene in familial multiple endocrine neoplasia type 1 and related states. Hum Mol Genet. 1997;6(7):1169-75.

67. Jamilloux Y, Favier J, Pertuit M, Delage-Corre M, Lopez S, Teissier MP, Mathonnet M, Galinat S, Barlier A, Archambeaud F. A MEN1 syndrome with a paraganglioma. Eur J Hum Genet. 2014;22(2):283-5.

68. Schussheim DH, Skarulis MC, Agarwal SK, Simonds WF, Burns AL, Spiegel AM, Marx SJ. Multiple endocrine neoplasia type 1: new clinical and basic findings. Trends Endocrinol Metab. 2001;12(4):173-8.

69. Welander J, Soderkvist P, Gimm O. Genetics and clinical characteristics of hereditary pheochromocytomas and paragangliomas. Endocr Relat Cancer. 2011;18(6):R253-76. 
70. Thakker RV. Multiple endocrine neoplasia type 1 (MEN1). Best Pract Res Clin Endocrinol Metab. 2010;24(3):355-70.

71. Johnston JJ, Rubinstein WS, Facio FM, Ng D, Singh LN, Teer JK, Mullikin $J C$, Biesecker LG. Secondary variants in individuals undergoing exome sequencing: screening of 572 individuals identifies high-penetrance mutations in cancer-susceptibility genes. Am J Hum Genet. 2012;91(1): 97-108.

72. Schulte KM, Mengel M, Heinze M, Simon D, Scheuring S, Kohrer K, Roher HD. Complete sequencing and messenger ribonucleic acid expression analysis of the MEN I gene in adrenal cancer. J Clin Endocrinol Metab. 2000; 85(1):441-8.

73. Shankar GM, Taylor-Weiner A, Lelic N, Jones RT, Kim JC, Francis JM, Abedalthagafi M, Borges LF, Coumans JV, Curry WT, et al. Sporadic hemangioblastomas are characterized by cryptic VHL inactivation. Acta Neuropathol Commun. 2014;2:167.

74. Dackiw AP, Cote GJ, Fleming JB, Schultz PN, Stanford P, Vassilopoulou-Sellin R, Evans DB, Gagel RF, Lee JE. Screening for MEN1 mutations in patients with atypical endocrine neoplasia. Surgery. 1999;126(6):1097-103. discussion 1103-1094

75. Bodian DL, McCutcheon JN, Kothiyal P, Huddleston KC, lyer RK, Vockley JG, Niederhuber JE. Germline variation in cancer-susceptibility genes in a healthy, ancestrally diverse cohort: implications for individual genome sequencing. PLoS One. 2014;9(4):e94554.

76. Casarim AL, Tincani AJ, Del Negro A, Aguiar CG, Fanni RV, Martins AS. Carotid body tumor: retrospective analysis on 22 patients. Sao Paulo Med J. 2014;132(3):133-9.

77. Offergeld C, Brase C, Yaremchuk S, Mader I, Rischke HC, Glasker S, Schmid KW, Wiech T, Preuss SF, Suarez C, et al. Head and neck paragangliomas: clinical and molecular genetic classification. Clinics (Sao Paulo). 2012; 67(Suppl 1):19-28.

78. Ricketts CJ, Forman JR, Rattenberry E, Bradshaw N, Lalloo F, Izatt L, Cole TR, Armstrong R, Kumar VK, Morrison PJ, et al. Tumor risks and genotypephenotype-proteotype analysis in 358 patients with germline mutations in SDHB and SDHD. Hum Mutat. 2010;31(1):41-51.

79. Reichman J, Healey WC. Amplification monitoring and maintenance in schools. ASHA. 1989;31(11):43-5.

80. Shamblin WR, ReMine WH, Sheps SG, Harrison EG Jr. Carotid body tumor (chemodectoma). Clinicopathologic analysis of ninety cases. Am J Surg. 1971;122(6):732-9.

81. Lopez-Jimenez E, Gomez-Lopez G, Leandro-Garcia LJ, Munoz I, Schiavi F, Montero-Conde C, de Cubas AA, Ramires R, Landa I, Leskela S, et al. Research resource: transcriptional profiling reveals different pseudohypoxic signatures in SDHB and VHL-related pheochromocytomas. Mol Endocrinol. 2010;24(12):2382-91.

82. Hiltemann S, Jenster G, Trapman J, van der Spek P, Stubbs A. Discriminating somatic and germline mutations in tumor DNA samples without matching normals. Genome Res. 2015;25(9):1382-90.

83. Ahn SM, Ansari AA, Kim J, Kim D, Chun SM, Kim J, Kim TW, Park I, Yu CS, Jang SJ. The somatic POLE P286R mutation defines a unique subclass of colorectal cancer featuring hypermutation, representing a potential genomic biomarker for immunotherapy. Oncotarget. 2016;7(42):68638-49.

84. Johanns TM, Miller CA, Dorward IG, Tsien C, Chang E, Perry A, Uppaluri R, Ferguson C, Schmidt RE, Dahiya S, et al. Immunogenomics of Hypermutated Glioblastoma: a patient with Germline POLE deficiency treated with checkpoint blockade immunotherapy. Cancer Discov. 2016;6(11):1230-6.

85. Bourdais R, Rousseau B, Pujals A, Boussion H, Joly C, Guillemin A, Baumgaertner I, Neuzillet C, Tournigand C. Polymerase proofreading domain mutations: new opportunities for immunotherapy in hypermutated colorectal cancer beyond MMR deficiency. Crit Rev Oncol Hematol. 2017;113:242-8.

86. Finocchiaro G, Langella T, Corbetta C, Pellegatta S. Hypermutations in gliomas: a potential immunotherapy target. Discov Med. 2017;23(125):113-20.

\section{Submit your next manuscript to BioMed Central and we will help you at every step:}

- We accept pre-submission inquiries

- Our selector tool helps you to find the most relevant journal

- We provide round the clock customer support

- Convenient online submission

- Thorough peer review

- Inclusion in PubMed and all major indexing services

- Maximum visibility for your research

Submit your manuscript at www.biomedcentral.com/submit
Biomed Central 